\title{
VALOR NUTRITIVO DE UMA PASTAGEM NATIVA DOMINADA POR Eragrostis plana Nees E SUA RELAÇÃO COM O PERFIL METABÓLICO DE VACAS PRIMÍPARAS SUPLEMENTADAS DA GESTAÇÃO AO PÓS-PARTO
}

\author{
NUTRITIVE VALUE OF A NATIVE PASTURE DOMINATED BY Eragrostis \\ plana Nees AND ITS RELATION WITH METABOLIC PROFILE OF \\ PRIMIPAROUS COWS SUPPLEMENTED FROM PREGNANCY TO \\ POSTPARTUM
}

\author{
Caius Barcellos de Pellegrini ${ }^{1 *}$ \\ Renato Borges de Medeiros ${ }^{1}$ \\ Silvane Barcelos Carlotto ${ }^{1}$ \\ Renata Porto Alegre Garcia ${ }^{1}$ \\ Celso Vargas Lisboa ${ }^{1}$ \\ Gilmar Bruning ${ }^{1}$ \\ 1 Universidade Federal do Rio Grande do Sul, Porto Alegre, RS, Brasil. \\ *Autor para correspondência - caiuspellegrini@hotmail.com
}

\section{Resumo}

Objetivou-se com este trabalho estimar a qualidade da massa de forragem de uma pastagem nativa com $70 \%$ de cobertura de capim-annoni (Eragrostis plana Nees) sob pastejo contínuo de vacas primíparas. As características químicas da forragem dos componentes folha e colmo de capim-annoni e espécies nativas avaliadas foram: digestibilidade in vitro da matéria orgânica (DIVMO), proteína bruta (PB) e fibra em detergente neutro (FDN). O perfil metabólico proteico e mineral no sangue das vacas foi relacionado com os suplementos sal comum, Fosbovi pronto ${ }^{\circledR}$, Foscromo seca ${ }^{\circledR}$ e Fosbovi reprodução ${ }^{2}$. Verificaram-se maiores teores de PB na folha e colmo de capim-annoni no inverno $(9,4 \%$ e 6,7$)$ e primavera $(8,9 \%$ e 6,6$)$, respectivamente. As variáveis metabólicas protéicas no sangue não diferiram entre suplementos $(\mathrm{P}>0,05)$, mas os níveis de albumina $(34,5$ a $25,3 \mathrm{~g} / \mathrm{L})$ e ureia $(36,2$ a 30,1 $\mathrm{mg} / \mathrm{dL}$ ) diminuíram do inverno para verão. Houve deficiência dos teores médios do mineral fósforo para vacas suplementadas com Foscromo seca ${ }^{\circledR}(3,9)$, Fosbovi pronto ${ }^{\circledR}(3,3)$ e sal comum $(2,2)$ na primavera e sal comum no verão $(2,9 \mathrm{mg} / \mathrm{dL})$. Vacas primíparas manejadas em pastagem nativa com predominância de $70 \%$ de cobertura de capim-annoni exigem suplementação do mineral fósforo com Fosbovi reprodução ${ }^{\circledR}$ nas estações da primavera e verão.

Palavras-chave: Digestibilidade da matéria orgânica; espécies nativas; fibra em detergente neutro; folha; proteína bruta.

\footnotetext{
Abstract

The objective of this research was to evaluate the quality of the forage mass of a native pasture covered by $70 \%$ of Eragrostis plana Nees (South African lovegrass) under continuous grazing of primiparous cows. The following chemical characteristics of forage components leaves and stems of South African lovegrass and native species were evaluated: organic matter in vitro digestibility (OMIVD), crude protein $(\mathrm{CP})$, and neutral detergent fiber (NDF). The protein and mineral metabolic profile in blood was associated with the supplements common salt, mineral salt, protein salt and reproduction salt. There was higher crude protein content in leaves and stems of South African lovegrass in winter (9.4\% and 6.7) and
} 
spring (8.9\% and 6.6), respectively. Metabolic protein in the blood did not differ among supplements $(\mathrm{P}>0.05)$, but levels of albumin ( 34.5 to $25.3 \mathrm{~g} / \mathrm{L})$ and urea (36.2 to $30.1 \mathrm{mg} / \mathrm{dL})$ decreased from winter to summer. There was deficiency of the average content of mineral phosphorus for cows supplemented with protein salt (3.9), mineral salt (3.3) and common salt (2.2) in spring and common salt (2.9 mg/ $\mathrm{dL}$ ) in summer. Primiparous cows managed on native pasture with a prevalence of $70 \%$ coverage of South African lovegrass need mineral phosphorus supplementation with reproduction salt in spring and summer.

Keywords: crude protein; leaf; organic matter in vitro digestibility; native species; neutral detergent fiber.

Enviado em: 14 janeiro 2012

Aceito em: 28 dezembro 2015

\section{Introdução}

A invasão de habitats pastoris por plantas exóticas é um fenômeno global, com graves consequências aos sistemas ecológicos, comprometendo a conservação dos ambientes de espécies nativas, comunidades e ecossistemas ${ }^{(1)}$. Por outro lado, pouco se sabe sobre as ameaças representadas por espécies exóticas invasoras para a biodiversidade, os recursos naturais dentro desses ecossistemas ${ }^{(2)} \mathrm{e}$ as alternativas de controle ambiental (3). No caso particular da vegetação da pastagem nativa do Bioma Pampa do Rio Grande do Sul (RS), a invasibilidade é facilitada pela alta frequência de espaços vazios originados pelas práticas de cultivo em áreas de pastagem nativa. Estes fatores de degradação respondem pela drástica redução da frequência de espécies nativas e perda do valor nutritivo da forragem produzida, abrangendo uma área de aproximadamente um milhão de hectares de pastagem nativa ${ }^{(4)}$. Entretanto, a pastagem nativa continua sendo a principal fonte de nutrientes do rebanho bovino do RS. Além disso, este ecossistema natural modificado apresenta variações nutricionais durante o ano, em virtude de variações climáticas, tipos de solos, composição botânica e estacionalidade da produção de forragem. Outras limitações nutricionais observadas na forragem são dos macro-minerais fósforo, cálcio, sódio, enxofre e magnésio, dos micro-minerais cobre e zinco $^{(5-6)}$ e de proteína bruta ${ }^{(7)}$. Neste contexto, é necessário desenvolver práticas de manejo racional para a utilização destes campos, em que a suplementação proteico-mineral constitui-se numa alternativa de baixo custo para completar a qualidade da forragem ofertada, principalmente, para vacas primíparas.

Uma ferramenta utilizada para verificar o balanço nutricional dos animais a campo é o perfil metabólico, uma vez que, em algumas situações, os desequilíbrios nutricionais podem influenciar as concentrações sanguíneas de alguns metabólitos ${ }^{(8)}$. O perfil metabólico se refere ao estudo de alguns componentes hematobioquímicos específicos que servem para avaliar, diagnosticar e prevenir transtornos metabólicos, uma vez que os desequilíbrios nutricionais são de difícil percepção e limitam a produção animal, diminuindo a rentabilidade da empresa pecuária ${ }^{(9)}$. Neste sentido, é fundamental caracterizar o valor nutritivo dos componentes estruturais do pasto ofertado e correlacioná-los com o perfil proteico-mineral dos animais.

Em condições de pastagem nativa no RS, estudos realizados com controle de ajuste de oferta de forragem (OF) determinaram variações na produção e na qualidade da forragem, as quais provocaram distintos desempenhos animais e de produtividade por área na recria de bovinos de corte ${ }^{(10-11)}$. A suplementação proteica de bovinos de corte em pastagem nativa no RS é uma alternativa nutricional para melhorar o desempenho animal frente a animais suplementados apenas com sal mineral ${ }^{(12)}$.

Neste sentido, este trabalho objetivou avaliar o valor nutritivo dos componentes estruturais de uma pastagem nativa com $70 \%$ de cobertura de capim-annoni e sua relação com perfil metabólico e produção de leite de vacas de corte recebendo ou não suplementação proteica e mineral.

\section{Material e Métodos}

O experimento foi conduzido em área de pastagem nativa dominada por Eragrostis plana Nees (capim-annoni), fazenda São Lucas, município de Rio Pardo, RS. A área experimental apresentava 
uma cobertura de $70 \%$ de capim-annoni. O restante da área era composto, em ordem decrescente de cobertura, pelas seguintes espécies de gramíneas e leguminosas: grama-de-forquilha (Paspalum notatum), pega-pega (Desmodium incanum), brizas (Briza subaristata, B.unioleae e B. poeamorpha), capim-caninha (Andropogon lateralis), grama-de-jardim (Axonupus affinis), flexilha (Stipa yourguensi), barba-de-bode (Aristida jubata) e cabelo-de-porco (Piptochaetium montevidensis).

Foram utilizadas 32 vacas primíparas mestiças Polled Hereford x Charolês x Nelore aos três anos de idade e avaliadas em pastagem nativa dominada por capim-annoni e submetidas aos seguintes suplementos: Sal Comum, Fosbovi Pronto ${ }^{\circledR}$, Foscromo Seca ${ }^{\circledR}$ e Fosbovi Reprodução ${ }^{\circledR}$. Os animais foram avaliados durante o período de gestação (inverno) e pós-parto (primavera e verão).

Os suplementos foram fornecidos à vontade em cochos cobertos com área disponível por animal (0,5 m), com revisão e reposição semanal (Tabela 1$)$.

Tabela 1: Níveis de garantia dos suplementos ${ }^{1}$

\begin{tabular}{|c|c|c|c|c|}
\hline Parâmetros & Sal comum & $\begin{array}{l}\text { Fosbovi } \\
\text { pronto® }\end{array}$ & $\begin{array}{c}\text { Foscromo } \\
\text { seca® }\end{array}$ & $\begin{array}{c}\text { Fosbovi } \\
\text { reprodução® }\end{array}$ \\
\hline Cálcio (g/kg) & - & 60,00 & 43,00 & 123,00 \\
\hline Fósforo $(\mathrm{g} / \mathrm{kg})$ & - & 45,00 & 30,00 & 90,00 \\
\hline Magnésio $(\mathrm{g} / \mathrm{kg})$ & - & - & 7,80 & - \\
\hline Sódio $(\mathrm{g} / \mathrm{kg})$ & 390,00 & 152,00 & 61,00 & 141,00 \\
\hline Iodo $(\mathrm{mg} / \mathrm{kg})$ & 25,00 & 50,25 & 30,00 & 75,00 \\
\hline Cobre (mg/kg) & - & $1.050,00$ & 400,00 & $1.500,00$ \\
\hline Cobalto $(\mathrm{mg} / \mathrm{kg})$ & - & 38,90 & 30,00 & 60,00 \\
\hline Ferro $(\mathrm{mg} / \mathrm{kg})$ & - & 1300,00 & 500,00 & $1.800,00$ \\
\hline Manganês (mg/kg) & - & 1000,00 & $1.050,00$ & $1.800,00$ \\
\hline Selênio (mg/kg) & - & 9,00 & 10,00 & 17,00 \\
\hline Zinco (mg/kg) & - & $2.520,00$ & $2.700,00$ & $4.500,00$ \\
\hline Cromo (mg/kg) & - & - & 10,00 & 20,00 \\
\hline Enxofre (g/kg) & - & 4,12 & 19,60 & 18,00 \\
\hline Flúor $(\mathrm{mg} / \mathrm{kg})$ máx & - & 450,00 & 300,00 & 900,00 \\
\hline Sol. P (\%) Ac. Cít. a $2 \%$ & - & 95,00 & 95,00 & 95,00 \\
\hline NNP (\%) & - & - & 6,75 & - \\
\hline $\begin{array}{l}\text { Eq. Protéico NNP (\%) } \\
\text { máx. }\end{array}$ & - & - & 42,18 & - \\
\hline Umidade (\%) máx. & - & - & 9,00 & - \\
\hline PB (\%) mín. & - & - & 46,00 & - \\
\hline
\end{tabular}

lFonte: (Departamento técnico da Companhia Zootécnica Agrária Tortuga).

$\mathrm{O}$ método de pastejo foi o contínuo com taxa de lotação variável. $\mathrm{O}$ ajuste da carga animal (CA) à oferta de forragem (OF) foi feito com o uso de animais reguladores. Em cada unidade experimental foram realizadas 34 estimativas visuais do rendimento de MS no pasto e cortadas seis amostras rente ao solo, de $0,25 \mathrm{~m}^{2}$, método da dupla amostragem. As amostras foram colocadas em sacos de papel e levadas à estufa de ar forçado a $65^{\circ} \mathrm{C}$ por $72 \mathrm{~h}$ para determinação do teor de matéria seca (MS).

A determinação do valor nutritivo dos componentes estruturais da fitomassa da pastagem nativa foi realizada em sub-amostras das avaliações de massa de forragem. As médias foram tomadas nos períodos do inverno, primavera e verão, através da separação botânica e morfológica (folha e colmo de capim-annoni e espécies nativas). As avaliações de forragem foram realizadas a cada 35 dias. Avaliaram-se os teores de proteína bruta (PB) pelo método micro Kjëldahl, técnica descrita pela $\mathrm{AOAC}^{(13)}$. O teor de fibra em detergente neutro (FDN) foi avaliado conforme Van Soest ${ }^{(14)}$, sendo corrigida para cinzas e proteína (FDNcp). A digestibilidade in vitro da matéria orgânica (DIVMO) foi 
determinada pelo método descrito por Tilley \& Terry ${ }^{(15)}$.

As coletas de sangue das vacas foram feitas nas datas do inverno (24/06/2006), primavera (28/10/2006) e verão (19/03/2007). Foram analisados os indicadores bioquímicos do status nutricional proteico (albumina, ureia) e mineral (fósforo, magnésio, sódio, potássio) pelo Laboratório de Veterinária, UFRGS.

O delineamento experimental foi o inteiramente casualizado com parcelas subdivididas no tempo, com quatro tratamentos e duas repetições de área (unidade experimental). Os dados coletados foram submetidos à análise de variância e quando detectada diferença entre os tratamentos, realizou-se o teste $t$ de Student (PDIFF) para comparação de médias, adotando-se 5\% de probabilidade. As análises foram feitas com auxílio do procedimento Mixed do aplicativo estatístico SAS.

\section{Resultados e Discussão}

Os teores médios estacionais de proteína bruta diferiram significativamente $(\mathrm{P}<0,05)$ no componente morfológico folha de capim-annoni (Figura 1).

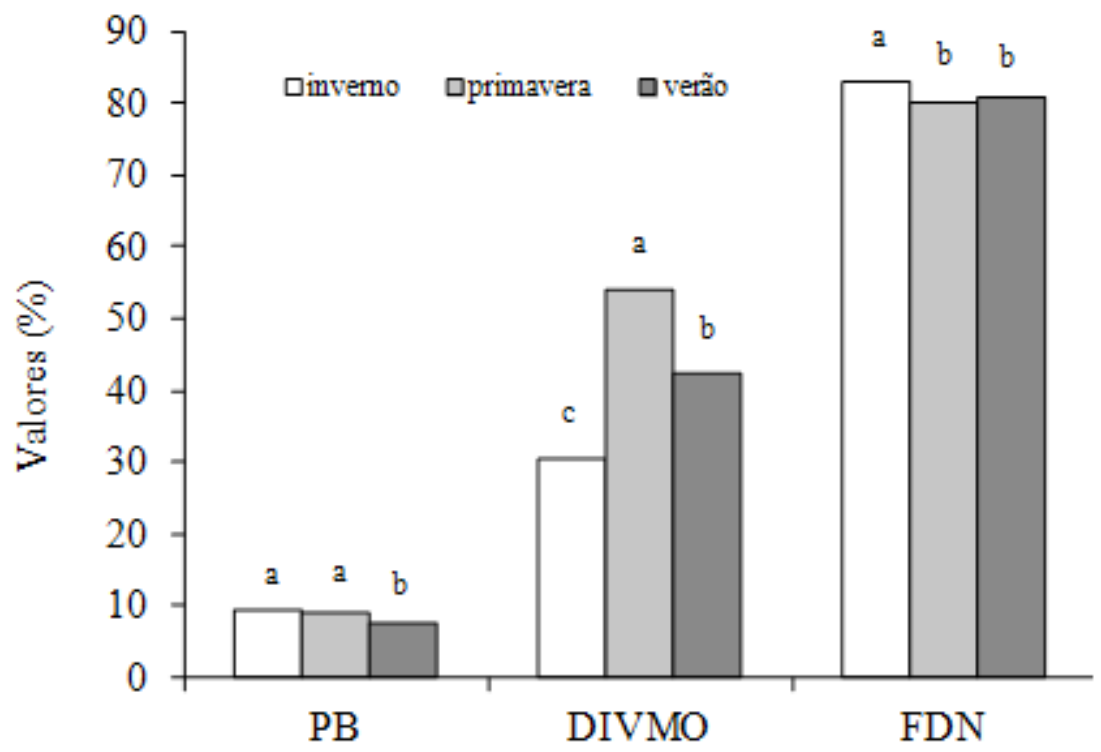

Parâmetros qualitativos

Figura 1: Valor médio de PB, DIVMO e FDN da folha de capim-annoni nas diferentes estações do ano, RS.

Os maiores teores médios de proteína bruta da folha de capim-annoni foram verificados nas estações do inverno e primavera $(9,4 ; 8,9 \%)$, respectivamente, diferindo do teor proteico do verão $(7,7 \%)$. $\mathrm{O}$ maior teor proteico da folha de capim-annoni pode ser atribuído a algumas características da planta invasora como porte vigoroso, alta produção de massa verde, adaptação a solos pobres e resistência ao frio ${ }^{(16)}$ e o surgimento de folhas novas.

Avaliações da pastagem nativa com dominância de capim-annoni mostraram baixos teores de proteína bruta e fibra em detergente neutro $(5,6 ; 71,6 \%$ e 4,$1 ; 69,9 \%)$ durante a estação quente, que foram verificados quando as disponibilidades de forragem foram superiores a $5 \mathrm{ton} / \mathrm{MS} / \mathrm{ha}^{(7-17)}$. Por outro lado, Alfaya et al. ${ }^{(18)}$, avaliando feno de capim-anonni, observaram diminuição dos teores proteicos médios aproximados $(7,8$ a 5,3\%), durante a primavera e verão referentes a cinco épocas de corte (30 a 150 dias). Assim, para a obtenção de maiores teores de proteína bruta da invasora capim-anonni sob pastejo, verifica-se quando as plântulas estão em desenvolvimento inicial na primavera e com 
disponibilidades de massa de forragem variando entre 2000 a $2500 \mathrm{~kg}$ de $\mathrm{MS} / \mathrm{ha}$.

$\mathrm{O}$ maior teor de FDN observados na folha no inverno deve-se à maturação fisiológica da planta, reflexo da diminuição do fotoperíodo e da temperatura, bem como ao acúmulo de material senescente e morto na área, oriundos do acúmulo de forragem ocorrido nesta mesma estação. Rocha et al. ${ }^{(19)}$ explicaram a conversão dos componentes estruturais das plantas forrageiras pela aceleração dos produtos fotossintéticos decorrido do avanço do estágio fenológico.

Os teores médios da qualidade nutricional do componente colmo de capim-annoni também diferiram $(\mathrm{P}<0,05)$ entre as estações do ano (Figura 2).

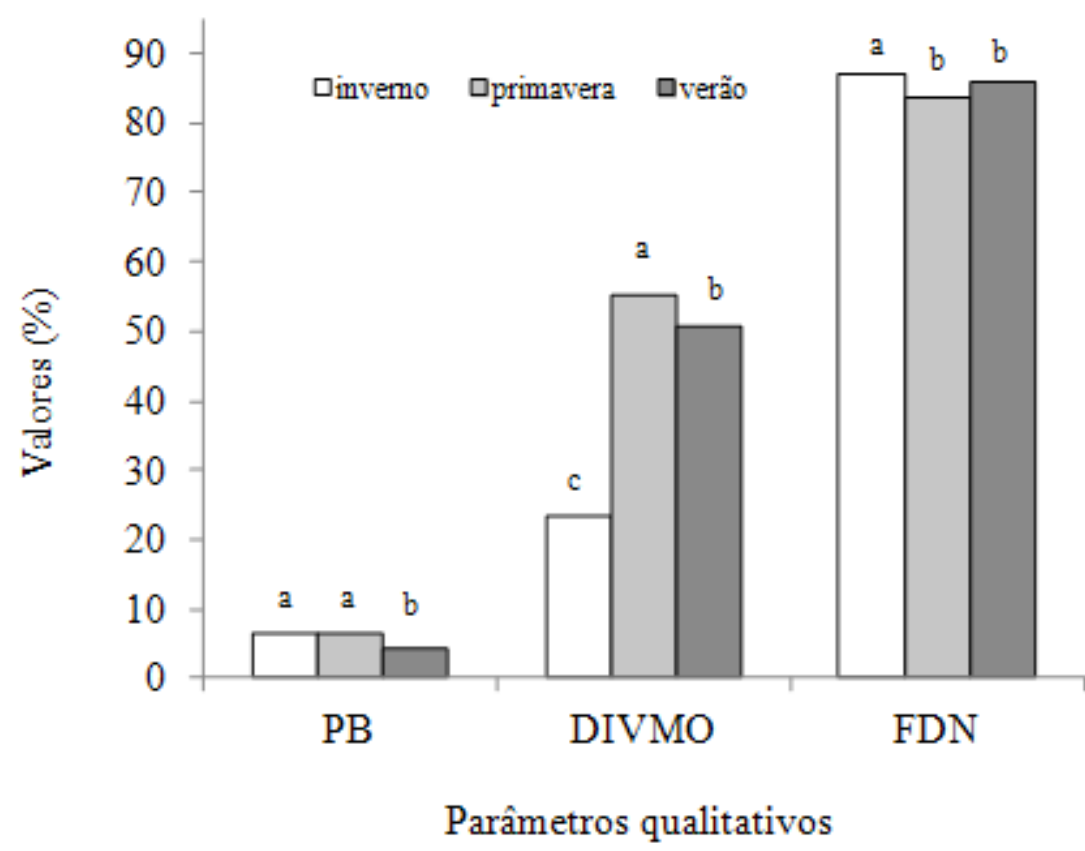

Figura 2: Valor médio de PB, DIVMO e FDN do colmo de capim-annoni nas diferentes estações do ano, RS.

Os maiores teores protéicos observados no colmo de capim-annoni no inverno e primavera $(6,7$; $6,6 \%)$ e menores no verão $(4,4 \%)$ apresentaram a mesma tendência do maior percentual de proteína bruta da folha de capim-annoni da estação fria. Os menores valores estimados nos parâmetros qualitativos (PB e DIVMO) do componente colmo de capim-annoni, quando comparado com a folha, estão relacionados com a maior proporção do componente parede celular. De modo geral, as folhas possuem maior percentual de PB e menores concentrações de FDN, em comparação aos colmos das plantas forrageiras ${ }^{(14)}$. A determinação dos parâmetros qualitativos (PB, FDN e DIVMO) do colmo complementa os resultados de análise nutricional da planta em avaliação.

Os teores protéicos de espécies nativas diferiram $(\mathrm{P}<0,05)$ entre as estações do ano (Figura 3). Os teores protéicos diferiram durante a estação da primavera quando comparados com inverno e verão (12,0; 9,7 e 9,2\%, respectivamente), enquanto que os teores de FDN $(66,3 ; 71,0$ e 69,0\%) e de DIVMO $(48,0 ; 52,0$ e 50,0\%) não diferiram entre si ( $\mathrm{P}>0,05)$.

O componente morfológico de espécies nativas apresentou maiores teores de $\mathrm{PB}$ em relação a folha e colmo de capim-annoni, em virtude da menor proporção de componentes da parede celular como colmos e inflorescências nestas espécies. A partir do verão, uma proporção expressiva de perfilhos de capim-annoni estão em fase final de desenvolvimento, elevando os pontos de crescimento e formando inflorescências que diminuem o valor nutricional da planta avaliada. 


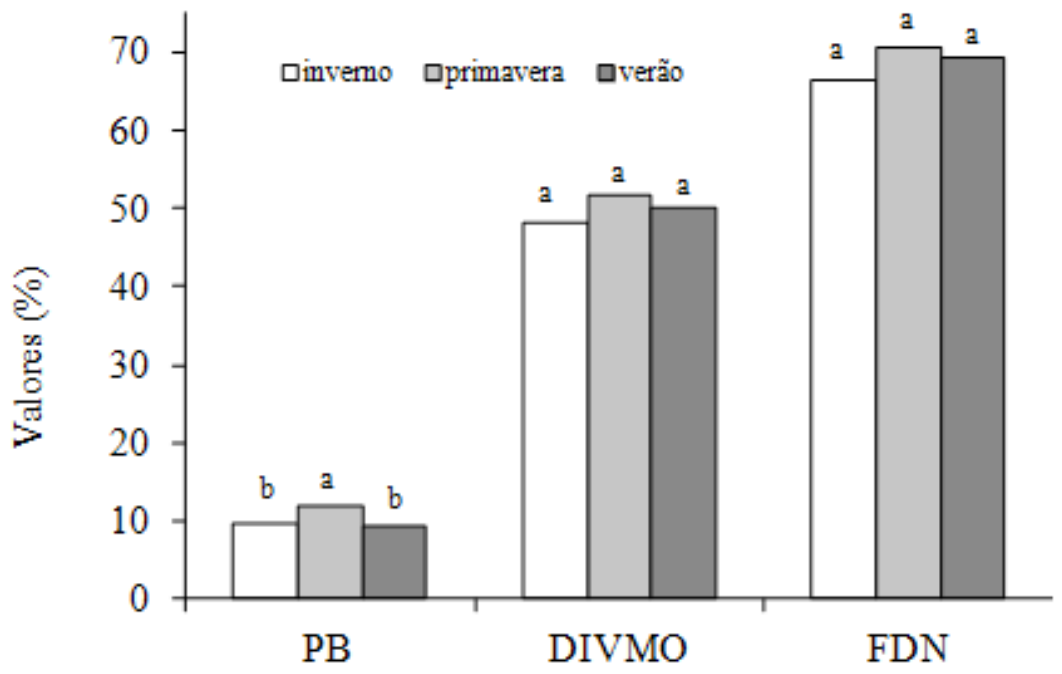

Parâmetros qualitativos

Figura 3: Valor médio de PB, FDN e DIVMO de espécies nativas nas diferentes estações do ano, RS.

No presente estudo, verificaram-se melhores constituintes nutricionais (PB, FDN e DIVMO) de espécies nativas quando comparados com valores de folha e colmo de capim-annoni, que confirmaram que esta invasora apresenta menor valor nutritivo do que espécies nativas da pastagem nativa. No entanto, o sobrepastejo de espécies nativas em área de pastagem nativa dominada pelo capim-annoni reduz as chances de os animais selecionarem forragem adequada às suas exigências nutricionais. É consenso geral que essa gramínea deve ser erradicada e/ou controlada, pois não apresenta vantagens em relação à qualidade nutricional da vegetação da pastagem nativa e, principalmente, pelo seu caráter de invasora. Além disso, esses resultados servem para elucidar a pesquisa científica dos valores nutricionais desta planta indesejável na composição botânica da pastagem nativa do Bioma Pampa, mas que esta invadindo outros biomas brasileiros ${ }^{(2)}$.

Com relação aos componentes proteicos registrados no sangue das vacas, não houve diferença significativa nos níveis de albumina e ureia $(\mathrm{P}>0,05)$, entre suplementos; contudo, ambos diminuíram nas estações do inverno para verão (Tabela 2).

Níveis insuficientes de albumina foram observados no perfil sanguíneo das vacas comparando-se os suplementos no verão $(25,3 \mathrm{~g} / \mathrm{L})$, confirmando o baixo teor proteico estimado na folha de capimanonni. O declínio dos níveis sanguíneos de albumina e ureia observados no sangue dos animais está positivamente correlacionado com os teores de proteína bruta (Pearson: $r=0,78 ; r=0,40)$ e digestibilidade in vitro da matéria orgânica $(\mathrm{r}=0,70 ; \mathrm{r}=0,50)$ do pasto, respectivamente, que diminuiu à medida que o desenvolvimento fenológico do pasto alcançou a maturidade.

Outro fator fisiológico dos animais lactantes foi destacado por Easdon et al. ${ }^{(21)}$, que observou diminuição do nível de albumina em vacas após o parto, em virtude da demanda de aminoácidos para a síntese de proteína do leite. Nível de albumina similar $(23,6 \mathrm{~g} / \mathrm{L})$ foi verificado por Peixoto et al. ${ }^{(22)}$ no sangue de vacas de cria avaliadas exclusivamente em pastagem nativa dominada por capimanonni.

Houve interação significativa $(\mathrm{P}<0,05)$ para o teor de fósforo no sangue das vacas entre os suplementos e as estações do ano (Tabela 2). O teor de fósforo limitante no perfil sanguíneo das vacas foi observado nos suplementos Foscromo seca ${ }^{\circledR}$, Fosbovi pronto ${ }^{\circledR}$ e sal comum na primavera. No verão, observouse nível de fósforo insuficiente para vacas suplementadas com sal comum. Valle et al.(23) também observaram níveis insuficientes de fósforo no sangue de vacas de cria avaliadas nos estágios do final da gestação $(1,56 \mathrm{mmol} / \mathrm{L})$ e início da lactação $(1,32 \mathrm{mmol} / \mathrm{L})$. González et al. ${ }^{(24)}$ verificaram média de fósforo de 1,68 mmol/L no plasma sanguíneo de novilhas de corte, indicando deficiência mineral na pastagem nativa durante o ano. 
Tabela 2: Perfil metabólico proteico e mineral no sangue de vacas primíparas

\begin{tabular}{|c|c|c|c|c|c|c|}
\hline \multirow[b]{3}{*}{$\begin{array}{c}\text { Estação } \\
\text { do ano }\end{array}$} & \multicolumn{4}{|c|}{ Suplementos } & \multirow[b]{3}{*}{ Média } & \multirow[b]{3}{*}{$\begin{array}{l}\text { Desvio } \\
\text { Padrão }\end{array}$} \\
\hline & $\begin{array}{c}\text { Fosbovi } \\
\text { reprodução@ }\end{array}$ & $\begin{array}{c}\text { Foscromo } \\
\text { seca }\end{array}$ & $\begin{array}{l}\text { Fosbovi } \\
\text { pronto }\end{array}$ & $\begin{array}{c}\text { Sal } \\
\text { comum }\end{array}$ & & \\
\hline & \multicolumn{4}{|c|}{ Albumina $(g / L)^{*}$} & & \\
\hline Inverno & 30,8 & 36,5 & 33,2 & 37,8 & $34,5 \mathrm{~A}$ & 0,89 \\
\hline Primavera & 35,3 & 34,5 & 30,7 & 33,9 & $33,6 \mathrm{~A}$ & 0,89 \\
\hline Verão & 26,5 & 26,1 & 24,2 & 24,2 & $25,3 \mathrm{~B}$ & 0,89 \\
\hline Média & 30,8 & 32,4 & 29,3 & 32 & & - \\
\hline Des. & 4,6 & 6,1 & 4,4 & 6,5 & - & - \\
\hline \multicolumn{7}{|l|}{ Padrão } \\
\hline & \multicolumn{4}{|c|}{ Ureia $(\mathrm{mg} / \mathrm{dL})^{*}$} & & \\
\hline Inverno & 31,4 & 37,0 & 43,6 & 32,8 & $36,2 \mathrm{~A}$ & 0,78 \\
\hline Primavera & 30,8 & 35,0 & 37,9 & 33,0 & $34,2 \mathrm{~A}$ & 0,78 \\
\hline Verão & 26,7 & 35,0 & 28,0 & 30,7 & $30,1 \mathrm{~B}$ & 0,78 \\
\hline Média & 29,6 & 35,7 & 36,5 & 32,2 & & - \\
\hline Des. & 3,0 & 1,9 & 3,5 & 2,1 & - & - \\
\hline \multicolumn{7}{|l|}{ Padrão } \\
\hline & \multicolumn{4}{|c|}{ Fósforo $(\mathrm{mg} / \mathrm{dL})^{*}$} & & \\
\hline Inverno & $7,2 \mathrm{Aa}$ & $7,3 \mathrm{Aa}$ & $5,0 \mathrm{Ab}$ & $4,5 \mathrm{Ab}$ & 6,0 & 0,87 \\
\hline Primavera & $5,0 \mathrm{Ba}$ & $3,9 \mathrm{Cab}$ & $3,3 \mathrm{Bbc}$ & $2,2 \mathrm{Bc}$ & 3,6 & 0,87 \\
\hline Verão & $6,6 \mathrm{Aa}$ & $4,9 \mathrm{Bb}$ & $5,2 \mathrm{Ab}$ & $2,9 \mathrm{Bc}$ & 4,9 & 0,87 \\
\hline Média & 6,2 & 5,4 & 4,5 & 3,2 & & \\
\hline Des. & 1,0 & 1,6 & 1,2 & 1,1 & - & - \\
\hline \multicolumn{7}{|l|}{ Padrão } \\
\hline
\end{tabular}

A deficiência de fósforo nos animais está relacionada com teores insuficientes deste mineral na dieta, predominando em regiões de solos pobres em fósforo e onde a alimentação suplementar não é usual ${ }^{(23)}$. Assim, vacas primíparas manejadas exclusivamente em pastagem nativa da Depressão Central do RS, região de campos mistos ou grossos e solos de baixa fertilidade, requerem suplementação Fosbovi reprodução® durante a primavera e o verão.

Os teores sanguíneos médios dos minerais sódio (142 mmol/L), potássio $(4,7 \mathrm{mmol} / \mathrm{L})$ e magnésio $(2,3 \mathrm{mg} / \mathrm{dL})$ também foram avaliados nas vacas, mas seus intervalos permaneceram normais entre os suplementos e estações do ano.

Esses resultados comprovam a importância da mensuração da característica nutricional da pastagem em ensaios de suplementação com bovinos para promover melhor entendimento da relação plantaanimal-suplemento. Por outro lado, a produção média diária de leite das vacas primíparas $(3,4 \mathrm{~kg})$ não diferiu $(\mathrm{P}>0,05)$ entre suplementos e diminuiu linearmente com o avanço do estágio de lactação (Tabela 3).

A diminuição da produção média de leite no presente estudo está positivamente correlacionada com os teores de proteína bruta (Pearson: $\mathrm{r}=0,62 ; \mathrm{P}<0,001$ ) e digestibilidade in vitro da matéria orgânica da folha de capim-annoni $(\mathrm{r}=0,50 ; \mathrm{P}<0,01)$, que diminuiu à medida que o desenvolvimento fenológico do pasto alcançou a maturidade. 
Tabela 3: Produção de leite de vacas primíparas em pastagem nativa dominada por capimannoni

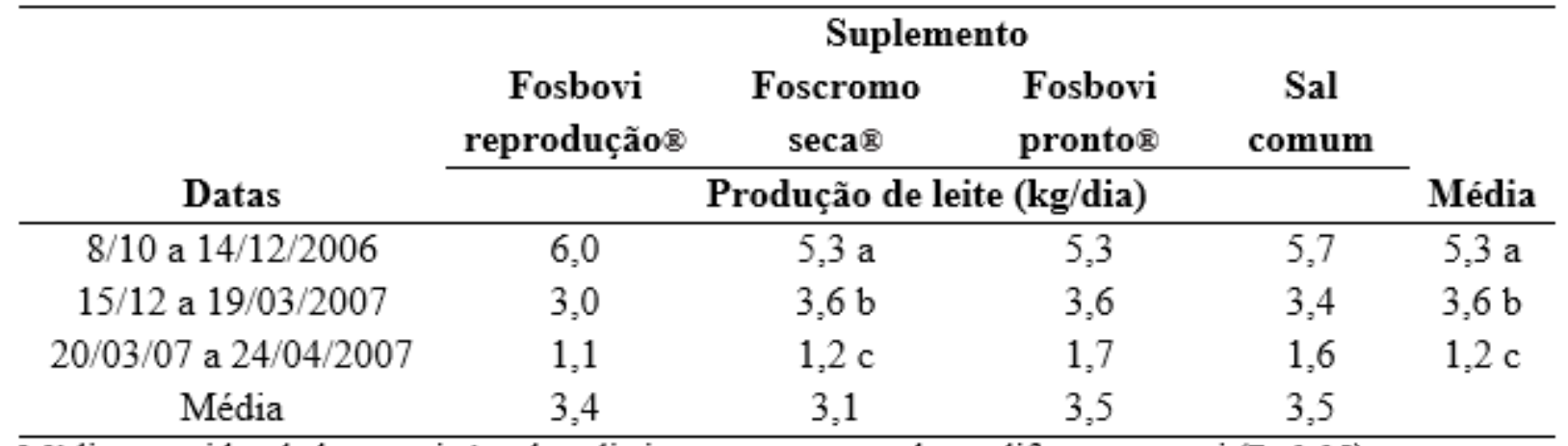

Médias seguidas de letras minúsculas, distintas na mesma coluna, diferem entre si $(\mathrm{P}<0,05)$.

Comportamento semelhante de produção média de leite sem pico de lactação foi observado em vacas em pastagem nativa $(3,25 \mathrm{~kg} / \mathrm{vaca})$, com maior produção aos 21 dias, decrescendo até os 63 dias ${ }^{(7)}$. As vacas perderam peso corporal no aleitamento, indicando que os teores de PB (5,64\%) e DIVMO $(29,72 \%)$ da pastagem nativa dominada por capim-annoni foram insuficientes para atender à demanda de nutrientes gastos na produção de leite, sendo necessário mobilizar reservas corporais ${ }^{(7)}$.

Restle et al. ${ }^{(25)}$ também relataram resposta linear decrescente da produção de leite $(5,3$ a 3,04 L/dia) dos 14 aos 154 dias de lactação, para vacas puras Charolês e Nelore multíparas manejadas em pastagem nativa de baixo valor nutricional.

A produção de leite das vacas primíparas mantidas em pastagem nativa dominada por capim-annoni foi expressa por uma regressão linear negativa $\left(Y=6,87-0,028 \mathrm{x} ; \mathrm{r}^{2}=0,87\right)$. A redução da produção de leite média, por vaca, segundo equação de regressão diminuiu numa taxa de $0,028 \mathrm{~L} /$ dia, sendo de 5,$3 ; 3,6$; e 1,2 L/dia, aos 47; 141; e 176 dias, respectivamente. O aumento na produção de leite relacionado aos melhores níveis de alimentação é relatado pela literatura científica. Quadros e Lobato ${ }^{(26)}$ observaram diferença significativa $(\mathrm{P}<0,05)$ na produção média de leite entre vacas manejadas em cargas de 240 e de $320 \mathrm{~kg} \mathrm{PV} / \mathrm{ha}(7,14$ e $6,15 \mathrm{~kg}$ de leite/dia, respectivamente); as vacas selecionaram diferentes disponibilidades de massa de forragem de pastagem nativa nas distintas cargas animais.

Por outro lado, Vaccaro e Dillard ${ }^{(27)}$ observaram correlação positiva entre o peso das vacas ao parto e a produção de leite, correlação essa intensificada quando há manutenção ou ganho de peso no período pré-parto.

Freetly e Cundiff( ${ }^{(28)}$ relataram que menores níveis nutricionais durante a fase de lactação podem resultar em menor produção de leite, em maior ou menor grau, conforme o nível de restrição alimentar ou de nutrientes. Porém, Osoro ${ }^{(29)}$ relatou que vacas de alto potencial leiteiro, quando manejadas em condições alimentares restritas, tanto em qualidade como em quantidade, repassam para suas crias, através do leite, os nutrientes destinados às reservas corporais e reprodução. A diminuição do nível protéico da fitomassa da pastagem nativa com $70 \%$ de cobertura de capim-annoni, no presente experimento, reduziu a produção média diária de leite das vacas, valor considero baixo. Outro fator agravante da redução da produção de leite dos animais, manejados sobre este ambiente de pastejo, é serem animais jovens, em fase de crescimento, com grande demanda de nutrientes. Neste sentido, os animais tiveram desempenhos produtivos limitados pelo baixo valor nutricional da pastagem nativa no verão, não contemplando a exigência nutricional das vacas primíparas.

\section{Conclusões}

A diminuição dos níveis proteicos dos componentes estruturais folha e colmo de capim-annoni da estação fria à estação quente está relacionada ao comportamento fisiológico da planta de ciclo estival. Os teores de albumina e ureia no sangue das vacas primíparas correlacionam-se positivamente com os 
teores de proteína bruta do pasto. A produção média de leite das vacas primíparas não foi influenciada pelos suplementos minerais e/ ou proteico e correlacionou-se positivamente com os teores de proteína bruta e digestibilidade in vitro da matéria orgânica da folha de capim-annoni. Vacas primíparas manejadas em pastagem nativa com predominância de $70 \%$ de cobertura de capim-annoni exigem suplementação Fosbovi reprodução® nas estações da primavera e verão.

\section{Referências}

1. Simberloff D. How common are invasion-induced ecosystem impacts? Biological Invasions. 2011; 13(5):1255-1268.

2. Schneider AA. A flora naturalizada no estado do rio grande do sul, Brasil: herbáceas subespontâneas. Biociências. 2007;15(2);257-268.

3. Goulart ICGR, Meroto Junior A; Perez NB; Kalsing, A. Controle de Capim-Annoni-2 (Eragrostis plana) com herbicidas pré-emergentes em associação com diferentes métodos de manejo do campo nativo. Planta Daninha. 2009;27(1):181-190.

4. Medeiros RB, Saibro JC, Focht T. Invasão do capim-annoni (Eragrostis plana Nees) no bioma Pampa do Rio Grande do Sul. In: Campos Sulinos - conservação e uso Sustentável da biodiversidade. Brasília: Ministério do Meio Ambiente, 2009:317-330.

5. Wunsch C, Barcellos JOJ, Prates ER, Costa EC da, Montanholi YR, Brandão F. Macrominerais para bovinos de corte nas pastagens nativas dos Campos de Cima da Serra, RS, Brasil. Ciência Rural. 2006;36(4):12581264.

6. Wunsch C, Barcellos JOJ, Prates ER, Grecellé RA, Costa EC da. Microminerais para bovinos de corte nas pastagens nativas dos Campos de Cima da Serra, RS, Brasil. Ciência Rural. 2005;35(4):903-908.

7. Cerdótes L, Restle J, Brondani IL, Osmari EK, Soccal DC, Santos MF dos. Desempenho produtivo de vacas de quatro grupos genéticos submetidos a diferentes manejos alimentares desmamadas aos 42 ou 63 dias pósparto. Revista Brasileira de Zootecnia. 2005:33(3):585-596.

8. Prestes DS, Filappi AR, Cecim M. Estado mineral de bovinos de corte em rebanhos suplementados no centro-oeste do Rio Grande do Sul. Archives of Veterinary Science. 2004;9(1):17-21.

9. Ciccioli NH, Wettemann RP, Spicer LJ, Lents CA, White FJ, Keisler DH. Influence of body condition at calving and postpartum nutrition on endocrine function and reproductive performance of primiparous beef cows. Journal of Animal Science. 2003;81:3107-3120.

10. Soares AB, Carvalho PC de F, Nabinger C, Semmelmann C, Trindade JK da, Guerra E, Freitas TS, Pinto CE, Fontoura Júnior JÁ, Frizzo A. Produção animal e de forragem em pastagem nativa submetida a distintas ofertas de forragem. Ciência Rural. 2005;35(5):1148-1154.

11. Pereira NF, Carvalho, PC de F, Nabinger C, Jacques AVA, Carassai IJ, Tentardini F. Estratégias de manejo da oferta de forragem para recria de novilhas em pastagem natural. Revista Brasileira de Zootecnia. 2009;38(8):1532-1542.

12. Montanholi YR, Barcellos JOJ, Borges Costa EC da, Wunsh, C, Prates ER. Ganho de peso na recria e desempenho reprodutivo de novilhas acasaladas com sobre ano. Pesquisa Agropecuária Brasileira. 2004;39(12):1253-1259.

13. ASSOCIATION OF OFFICIAL ANALYTICAL CHEMISTRY - AOAC. Official methods of analysis. 16 nd ed. Arlington: AOAC, 1995. 1141p.

14. Van Soest PJ, Robertson JB, Lewis BA. Methods for dietary fiber, neutral detergent fiber and nonstarch polysaccharides in relation to animal nutrition. Journal of Dairy Science. 1991;74(10):3583-3597. 
15. Tilley JMA, Terry RA. A two stage technique for the in vitro digestion of forage crops. Journal of the British Grassland Society. 1963;18(2):104-111.

16. Reis JCL, Coelho RW. Controle do capim-annoni em campos naturais e pastagens. EMBRAPA Clima Temperado: Pelotas, 2000. 21p.

17. Souza ANM, Rocha MG, Roso D, Pötter L, Rosa ATN, Ilha GF, Confortin ACC. Productivity and reproductive performance of grazing beef heifers bred at 18 months of age. Revista Brasileira de Zootecnia. 2012;41(2):306-313.

18. Alfaya H, Suñé LNP, Siqueira CMG, Silva DJS da, Silva JB da, Pederzolli EM, Lüeder WE. Efeito da amonização com uréia sobre os parâmetros de qualidade do feno do capim-annoni-2 (Eragrostis plana Nees). Revista Brasileira de Zootecnia. 2002;31(2):842-851.

19. Rocha MG, Quadros FLF, Glienke C.L., Confortin ACC, Costa VG da, Rossi GE. Avaliação de espécies forrageiras de inverno na Depressão Central do Rio Grande do Sul. Revista Brasileira de Zootecnia. 2007;36(6):1990-1999.

20. Kaneko JJ. Clinical Biochemistry of Domestic Animals. Academic Press Inc. New York. 1989. 842p.

21. Easdon MP, Chesworth JM, Aboul-Ela MBE, Henderson GD. The effect of undernutrition of beef cows on blood hormone and metabolite concentrations post-partum. Reproduction Nutrition Development. 1985;25(1A):113-126.

22. Peixoto LA de O, Brondani IL, Nörnberg JL, Restle J, Alves Filho DC, Pazini M, Coradini MT, Santos CVM dos. Perfil metabólico protéico e taxas de concepção de vacas de corte mantidas em pastagem natural ou suplementadas com farelo de trigo com ou sem ureia. Ciência Rural. 2006;36(6):1873-1877.

23. Valle S de F, González FHD, Rocha D, Scalzilli HB, Campo R, Larosa VL. Mineral deficiencies in beef cattle from southern Brazil. Brazilian Journal of Veterinary Research and Animal Science. 2003;40(supl.): 18731877.

24. González FHD, Conceição TR, Siqueira AJS, La Rosa VL. Variações sanguíneas de uréia, creatinina, albumina e fósforo em bovinos de corte no Rio Grande do Sul. Hora Veterinária. 2000;20:59-62.

25. Restle J, Pacheco OS, Moletta JL, Brondani IL, Cerdótes L. Grupo genético e nível nutricional pós-parto na produção e composição do leite de vacas de corte. Revista Brasileira de Zootecnia. 2005;32(3):585-597.

26. Quadros SAF, Lobato JFP. Efeitos da lotação animal na produção de leite de vacas de corte primíparas. Revista Brasileira de Zootecnia. 1996;26(1):27-33.

27. Vaccaro R, Dillard EU. Relationship among dam's weight changes to calf's growth rate in Hereford cattle. Journal of Animal Science. 1966;25(8):1063-1068.

28. Freetly HC, Cundiff LV. Reproductive performance, calf growth, and milk production of first calf heifers sired by seven breeds and raised on different levels of nutrition. Journal Animal Science. 1998;76(6):15131522.

29. Osoro KO. Manejo de las reservas corporales y utilización del pasto en los sistemas de producción de carne com vacas madres estabelecidos en zonas húmedas. Producción y Sanidad Animal. 1989;4(3):1-23. 